\title{
ENTRE HISTÓRIA, MEMÓRIA E ESQUECIMENTO: NARRATIVAS SOBRE A IMPRENSA JUAZEIRENSE
}

\author{
Andrea Cristiana Santos ${ }^{1}$
}

\section{Resumo:}

Este artigo faz uma análise das obras de João Fernandes da Cunha e Walter de Castro Dourado para compreender como se construiu uma memória sobre a imprensa da cidade de Juazeiro, norte da Bahia. A partir da inter-relação entre a história, a memória e esquecimento, estas obras podem ser consideradas um lugar de memória, no qual se privilegiou uma narrativa ancorada na tradição, noções de pertencimento e de identidade. Elas também se tornaram documentos-monumentos, que influenciaram a produção de um discurso fundador sobre a imprensa e devem ser problematizados pelos pesquisadores como fontes sujeitas à interpretação em busca dos vestígios sobre a ação dos primeiros comunicadores e dos seus produtos-jornais.

Palavras-chave: História; Memória; Esquecimento; História da Comunicação.

\section{Abstract:}

This article analyzes the works of João Fernandes da Cunha and Walter Castro Gold to understand how to build a memory on the press of the city of Juazeiro, north of Bahia. From the inter-relationship between history, memory and forgetting, these works can be considered a place of memory, which favored a narrative anchored in tradition, notions of belonging and identity. They also become document-monuments that influenced the production of a speech was on the press and should be problematized by researchers as sources subject to interpretation in search of traces of the action of the first communicators and their products-newspapers.

\footnotetext{
${ }^{1}$ Doutoranda do Programa de Pós-Graduação em Comunicação, da Universidade Federal do Rio de Janeiro. Jornalista, Mestre em História Social pela Universidade Federal da Bahia e professora do curso de Jornalismo em Multimeios da Universidade do Estado da Bahia. E-mail: andcsantos@uneb.br.
} 


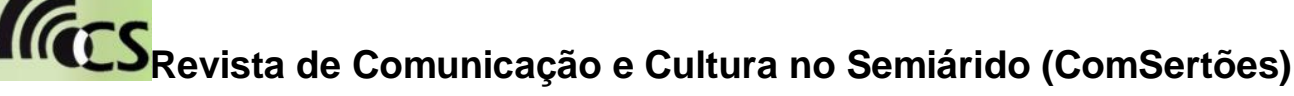

Keywords: History; Memory; Forgetting; History of Communication.

\section{Resumen:}

En este artículo se analiza la obra de João Fernandes da Cunha y Walter Castro de Oro y comprender cómo construir una memoria en la prensa de la ciudad de Juazeiro, en el norte de Bahía. De la interrelación entre la historia, la memoria y el olvido, estas obras se pueden considerar un lugar de la memoria, lo que favoreció un relato anclado en la tradición, las nociones de pertenencia e identidad. También se convierten en documentos-monumentos que influyeron en la producción de un discurso estaba en la prensa y debe ser problematizada por los investigadores como fuentes sujetas a la interpretación en busca de las huellas de la acción de la primera comunicadores y sus productos-periódicos.

Palabras claves: Historia; Memoria; Olvido; Historia de la Comunication.

\section{INTRODUÇÃO}

23 de Novembro de 1947. O morador da cidade baiana de Juazeiro recebia mais uma edição de $O$ Sertão, editado pelo tipógrafo José Diamantino de Assis. Na contracapa do jornal, o colunista Walter de Castro Dourado alertava o leitor para as dificuldades que os futuros historiadores teriam para reconstruir o passado da urbe, em decorrência das transformações sociais no ambiente urbano.

Walter de Castro Dourado lamentava o desaparecimento de alguns monumentos históricos. Ele não encontrava os vestígios do primeiro templo religioso em devoção a Nossa Senhora das Grotas e que deu origem à cidade. A sede da igreja matriz, construída em 1854, havia passado por várias reformas na sua estrutura, o que prejudicava a reconstituição do formato original; o antigo estádio do Prado, onde se praticavam os primeiros jogos de turfe, fora destruído; o Cinema Smart e o Teatro Sant'Anna também tiveram a sede demolida. 
Ao presenciar a ausência desses marcos arquitetônicos, Walter de Castro Dourado temia que não houvesse mais vestígios nem documentos para os futuros pesquisadores da história local. Ao final da coluna, vaticinava o destino da urbe: tudo se transformou, evoluiu, civilizou-se.

Essa percepção da aceleração do tempo e das mudanças o levava a nutrir o desejo de deixar um registro sobre o passado. Ele passou a recolher os documentos que ainda existiam e a coletar experiências dos homens e das mulheres para construir uma história sobre a cidade e seus personagens, ou vultos do passado como denominava.

\section{Walter de Castro Dourado não era o único a pensar sobre isso}

Dois anos depois, em 1949, o Instituto Geográfico e Histórico da Bahia, por ocasião das festividades do quarto centenário da cidade de Salvador, capital do estado, incentivou intelectuais e professores a contar parte da história dos municípios baianos. O professor e jornalista João Fernandes de Cunha iniciou um estudo que se propôs a narrar aspectos históricos do município, desde a ocupação das terras sertanejas ao desenvolvimento da imprensa.

Era preciso narrar acontecimentos históricos para que os futuros moradores soubessem da origem da cidade e para que o véu do esquecimento não recaísse sobre ela e sobre os habitantes. O estudo foi apresentado no Primeiro Congresso de História da Bahia e foi o único realizado por um município do interior.

Nos anos posteriores, a preocupação em construir uma narrativa histórica foi recorrente. No centenário da cidade em 1978, foram publicados dois livros que construíram um discurso sobre a história da cidade: Memória Histórica de Juazeiro, por João Fernandes da Cunha (1978), recuperando parte do estudo realizado no ano de 1949; e a coletânea Juazeiro ano 100: lances de sua história, por uma série de escritores locais, entre eles Jorge de Souza Duarte e Walter de Castro Dourado (1978). Na década de 1980, foram 
realizadas outras publicações ${ }^{2}$, com a intenção de registrar a evolução histórica, política, econômica e cultural do município.

Estas duas obras são relevantes porque elas se instituem como importantes fontes disponíveis aos pesquisadores na ausência de documentos primários localizados em acervos públicos e privados. Além disso, ambos autores podem ser considerados como guardiães da memória, pois coletaram documentos, recolheram informações e fizeram um registro de natureza histórica. Mesmo que os textos não discriminem as fontes históricas, eles exercitaram um ofício de narrar o passado e as narrativas constroem tessituras entre relatos de fatos históricos e memórias.

Neste artigo, propomos-nos analisar essas obras como um lugar de memória, conforme a concepção de Pierre Nora (1993), criadas a partir da compreensão de que as memórias não são espontâneas, sendo necessário registrar eventos, criar arquivos, organizar celebrações, ancorar o passado ao presente. Esses lugares, construídos simbolicamente, proporcionam ainda uma “identificação de um discurso individual com outro coletivo" (1993, p. 25).

Ao longo dos anos, pesquisadores e pessoas interessadas em conhecer a história da cidade utilizam essas obras, procurando seguir os rastros e os vestígios do passado. Esses rastros serão compreendidos, neste artigo, em um quadro conceitual de uma escrita da história, uma operação historiográfica, como recomenda Michel de Certeau (2008). Para o historiador, o conhecimento histórico é um fazer-se, que organiza procedimentos próprios ao objeto analisado e seus métodos de pertinência. Esta operação historiográfica deve ser compreendida em relação a três aspectos: um lugar, no qual se instauram os métodos, os interesses e a organização dos documentos; os procedimentos de análise, determinado pela interpretação; e a construção de um texto em uma escritura, uma narratividade. Neste processo, a escrita é uma prática social que estabelece um diálogo intermitente com o leitor.

\footnotetext{
${ }^{2}$ Entre as publicações: o livro Juazeiro da Bahia à luz de sua história, de Walter de Castro Dourado (1985); Juazeiro, na esteira do tempo, do médico e ex-prefeito Edson Ribeiro (2005); e Juazeiro nos caminhos da História (1986), de Jorge de Souza Duarte, entre outros.
} 
Seguindo estes procedimentos metodológicos, este artigo se propõe a analisar a obra de João Fernandes da Cunha e o artigo de Walter de Castro Dourado em busca dos vestígios e fragmentos sobre a imprensa juazeirense na primeira metade do século XX (1901-1950). A nossa intenção é refletir como essas obras podem contribuir para se construir uma história dos processos comunicativos em Juazeiro.

\section{Conhecendo o passado, esse território desconhecido}

O centenário da cidade, no ano de 1978, foi um momento especial para que a população juazeirense tivesse acesso às lembranças sobre o passado e marcos culturais de uma época. Esse chamado ao passado serviu para construir uma identidade e uma noção de pertencimento com o lugar, as pessoas, o espírito citadino.

$\mathrm{Na}$ imprensa local $^{3}$, jornalistas e professores procuravam reconstituir quadros de referência sobre a cidade, os seus habitantes para que acontecimentos, situações e relatos sobre os primeiros moradores, pudessem ser lembrados e os seus rastros não fossem apagados. Como afirma Maurice Halbwachs, para "melhor me recordar eu me volto para eles, adoto momentamente seu ponto de vista, entro em seu grupo, do qual continuo a fazer parte, pois sofro ainda seu impulso e encontro em mim muito das ideais e modos de pensar a que não teria chegado sozinho" (2004, p. 31).

Para ter acesso a esse passado, precisamos das lembranças de outras pessoas tanto para confirmar as nossas próprias quanto para lhes dar continuidade. No processo de intercambiar as próprias recordações e costurálas em uma narrativa, podemos rever os componentes pessoais para adequar o passado coletivamente relembrado às necessidades do presente, como nos fala David Lowenthal (1998).

Neste processo de ir ao encontro das lembranças que são reconstituídas na relação tempo, espaço e nas comunidades de afeto, inicia-se um processo

\footnotetext{
${ }^{3}$ O jornal Rivale publicou edições especiais a cada mês de aniversário da cidade, no período de 1972 até 1978, abordando costumes, tradições, história da navegação pelo rio São Francisco e a imprensa.
} 
de construção de uma memória coletiva, apoiada nos enquadramentos sociais produzidos por pessoas encarregadas de construir essas narrativas.

David Lowenthal (1998) considera ainda que, para termos acesso ao passado, podemos recorrer à história, à memória e aos fragmentos. A história é um processo verificável com base em documentos; a memória depende dos processos de seleção e de esquecimento; e os fragmentos são resíduos, artefatos que podem permitir o acesso ao passado.

Ao publicarem os relatos sobre o passado da cidade, João Fernandes da Cunha e Walter de Castro Dourado demonstravam que tinham a intenção de perpetuar para as futuras gerações informações históricas sobre a cidade e seus personagens. Foi sob a perspectiva da história e da memória que os autores reconstruíram parte do passado. E, no presente, essas obras podem ser compreendidas como artefatos, fragmentos sujeitos à interpretação.

Podemos considerar os autores como senhores da memória responsáveis por construir tessituras entre o que foi vivido, o que ainda se fazia lembrança e o que ficaria registrado para a posterioridade. Para o historiador Jaques Le Goff, constituir uma memória, tal como ocorreu na transição das sociedades orais para a escrita, é uma das grandes preocupações das classes, dos grupos, dos indivíduos que dominaram e dominam as sociedades históricas (1994, p.426).

Ao escreverem as obras, os autores devolveram esses escritos à população como documentos, no sentido de que a escrita tem a função de comunicar através do tempo, do espaço e fornece ao homem um processo de marcação, memorização e registro, como esclarece Le Goff (1994).

Ao mergulhar na leitura das obras de João Fernandes da Cunha e Walter de Castro Dourado, fica-nos a impressão de que os autores pareciam estar receosos de serem acometidos por uma amnésia coletiva, já que o ambiente urbano se modificava com a destruição de marcos arquitetônicos simbólicos. Na década de 1950, a população presenciou a demolição da estação ferroviária, após a construção da ponte Presidente Dutra. Também havia transformações nos hábitos culturais com a chegada da eletricidade, a 
implantação de alto-falante e do sistema de radiodifusão - Rádio Juazeiro -, em 1953 (DIAS, 1982).

Diante do receio da perda de referência social, os autores construíram uma narrativa que privilegiou um apelo à tradição e uma reverência a um passado glorioso, próspero.

Assim, as narrativas podem ser compreendidas como obras monumentos. Os monumentos, segundo a concepção de Le Goff, têm como características o ligar-se ao poder da perpetuação, voluntária ou involuntária, das sociedades históricas, conformadas por relações de forças de quem detinha o poder (1994).

Também devemos problematizar que é a ação dos homens no tempo e no espaço que transforma estes documentos em monumentos. O pesquisador que tem acesso a esses escritos deve seguir a recomendação metodológica que recomenda verificar as possibilidades da escrita da história, perceber as lacunas, os rastros, vestígios e as condições de produção destes documentos (LE GOFF, 1994).

Como pesquisadores de uma história da imprensa, compreendemos ainda que estes documentos-monumentos são artefatos, fragmentos, resíduos de um passado e não devemos desprezá-los. São fontes disponíveis para a construção de uma narrativa sobre os processos comunicacionais, principalmente em cidades em que os arquivos públicos não conservaram a maior parte dos documentos primários ${ }^{4}$.

Desta forma, essas obras podem trazer os vestígios da produção jornalística em uma relação com o presente, pois, como afirma David Lowenthal, as lembranças também se alteram quando revistas, aquilo que parece haver acontecido passa por contínua mudança.

\footnotetext{
${ }^{4}$ Para ter acesso aos jornais, existem acervos como os da Fundação Regional Museu do São Francisco e o trabalho de pesquisa da professora Odomaria Bandeira Macedo com o Arquivo Maria Franca Pires, que reúne impressos publicados no século XX, localizado na Universidade do Estado da Bahia, campus Juazeiro-BA.
} 
Sendo assim, é necessário reinterpretar estes relatos e encontrar elementos para construir uma história da imprensa local, que, junto com outros documentos, evidenciem aspectos dos processos comunicativos.

João Fernandes da Cunha, a cidade, a imprensa

O autor de Memória Histórica de Juazeiro João Fernandes da Cunha nasceu na cidade juazeirense em 21 de maio de 1921. Os seus parentes exerceram cargos políticos na região: o tio-avô Joaquim Jerônimo Fernandes da Cunha foi promotor, juiz de comarca, deputado pela Assembleia Provincial, no século XIX, e senador. João Fernandes da Cunha teve a formação educacional em Juazeiro e, somente aos 19 anos, pode deslocar-se para estudar em Salvador. Também foi professor e fundador do Arauto.

Nos anos de 1940, fez concurso para o Banco do Brasil e, em 1945, se graduou em Ciências Contábeis e em Ciências Econômicas, pela Universidade Federal da Bahia (UFBA). Em 1952, integrou a primeira turma de formandos em Jornalismo e Comunicação da Bahia. Também foi professor do curso de Ciências Econômicas, da universidade baiana, a partir do ano de 1955.

No prefácio ao seu livro, o autor diz que sua obra é a contribuição de um filho a sua terra, em uma demonstração do amor à cidade, onde foi "despertado para a vida e onde recebeu o amparo de Nossa Senhora das Grotas, padroeira do município".

Como um filho da terra, ele utilizou de memórias familiares para oferecer um testemunho e compartilhar pontos de vista de um ou mais grupos sociais. Ao narrar a história da cidade, João Fernandes da Cunha entrelaça aspectos da trajetória política, econômica, social e cultural do município.

$O$ jornalista ressaltou as condições geográficas que permitiram $O$ desenvolvimento de uma cidade próspera, às margens do São Francisco. A expansão dos sertanistas que desbravaram o território longe dos centros e das capitais permitiu a construção de núcleos de povoamento. Partia-se das terras 


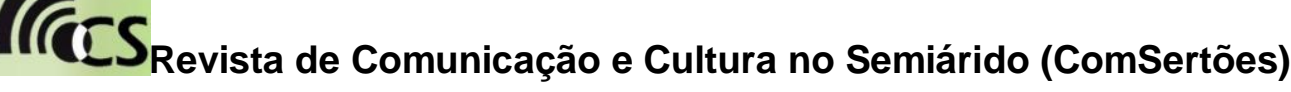

litorâneas para o interior, e tudo isso produzia deslocamento de pessoas, mercadorias e percepções de mundo.

A entrada dos sertões marcou também a possibilidade de acesso às terras do norte do país e do centro-oeste. Pela estrada da Passagem do Juazeiro, podia-se atravessar o rio e permitir o acesso aos estados do Ceará, Goiás, Piauí. Assim, a estrada permitiu a comunicação, compreendida como fluxo, de uma região a outra. Toda essa condição geográfica levaria a cidade a ostentar o título de "grande empório do sertão", denominada pelo engenheiro e geógrafo Teodoro Sampaio, em expedição à região, no final do século XIX.

$\mathrm{Na}$ sua construção narrativa, João Fernandes Cunha narrou a trajetória do município a partir dos grandes acontecimentos - o desbravamento do sertão - e dos homens que foram responsáveis pelo desenvolvimento da cidade. Sabemos, como assinala Le Goff (1994), sobre o risco de se construir uma narrativa histórica centrada nas limitações do singular ou das narrativas de grandes personagens.

Contudo, esta obra não pode ser desprezada, pois é um documento, uma construção simbólica sobre um tempo. Podemos, como afirma Le Goff, "questionar a documentação histórica sobre as lacunas, interrogar-nos sobre o esquecimento; os hiatos, os espaços brancos da história", pois cabe ao historiador "fazer a história a partir dos documentos e das ausências de documentos" (1994,p. 109).

Assim, consideramos a obra como um testemunho sobre um tempo e um espaço que ele acreditava que tendia a desaparecer, inclusive a imprensa, como assinalou, temeroso de que ela sucumbisse.

Mas como ele reconstrói esse tempo passado e o que ele nos conta sobre a imprensa? Como membro de um grupo social, João Fernandes da Cunha mobiliza lembranças coletivas para sustentar identidades duradouras. Os grupos sociais são representados a partir de recordações familiares. Nessa narrativa histórica, o tio-avô do autor, Joaquim Jerônimo Fernandes da Cunha, ocupou um lugar central, principalmente quando é relatada a construção da Estrada de Ferro da Bahia ao São Francisco, que teve a construção autorizada 
em 21 de junho de 1852. Foi a segunda estrada de ferro do país, e a primeira interligava o Rio de Janeiro a Minas Gerais. O fenômeno da construção da estrada significava a abertura de novas vias de comunicação e o maior fluxo de pessoas pelo sertão brasileiro.

Com a estrada de ferro, a cidade apresentava "invejável grau de crescimento e de progresso", comparada às outras cidades, às margens do rio São Francisco, o que permitiu o surgimento de outros bens culturais como a imprensa, o teatro, sociedades filarmônicas para atender aos processos de mediação social. Estava assim consolidada uma operação historiográfica que procurava associar a expansão da malha ferroviária ao progresso e ao desenvolvimento da imprensa.

\footnotetext{
"No ritmo de civilização que tomou Juazeiro, decorrente do crescimento de sua população, não poderiam deixar os seus habitantes de voltar suas atenções para a existência de um jornal, que possibilitasse a todos o conhecimento de suas necessidades, o direito de reclamá-las, a manifestação pública de suas opiniões e o ensejo de aplaudir as boas obras que se fossem realizando (CUNHA,1978, p 136).
}

Para o autor, a imprensa se constituía em uma instituição para atender as demandas do público e permitindo a construção de redes de sociabilidade. Os jornalistas eram literatos, professores e intelectuais que participavam da construção da esfera pública, "elevavam o espírito da população e promoviam cultura e educação", como ressaltou João Fernandes da Cunha.

Essa imprensa surgiu no final do século XIX. Em 1885, o comerciante Raimundo de Azevedo adquiriu uma prensa tipográfica para imprimir boletos, notas e um jornal sob a responsabilidade do tipógrafo Clóvis de Oliveira Mudo. Dez anos depois, em 1895, Clóvis lançou O Sertanejo, com redação do professor Atanázio Aquino Nazareno. A publicação do impresso não foi aceita por Azevedo, que, ao saber da publicação, mandou queimar os exemplares e demitiu o operário. Para o professor João Fernandes da Cunha, "Clóvis perdeu o emprego, mas foi projetado como pioneiro da imprensa de jornal na região" (1978, p.137). 
Este episódio é questionado pelo professor Walter de Castro Dourado no texto que publicou sobre a história da imprensa (1978). Para ele, o primeiro impresso foi $A$ Cidade de Juazeiro, bissemanário editado em $1^{\circ}$ de maio de 1896, por Raimundo Azevedo na tipografia Azevedo \& Companhia. Para Dourado, o jornal teve maior periodicidade, circulou durante um ano e tinham sido encontrados exemplares na biblioteca do Clube Comercial de Juazeiro. Já O Sertanejo teria sido distribuído para um círculo restrito de pessoas com acesso à tipografia onde trabalhava Clóvis Oliveira Mudo.

Esse acontecimento nos permite pensar sobre as relações de poder relacionadas ao surgimento da imprensa. Clóvis de Oliveira Mudo não tinha posses econômicas e era um assalariado da empresa de Raimundo Azevedo. O jornal que publicou não passou de uma edição, que fora destruída assim que o dono da tipografia obteve conhecimento.

\section{Posteriormente, outros tipógrafos e jornalistas surgiram na esfera pública.}

Um dos jornalistas que tem o perfil retratado por João Fernandes da Cunha foi Joaquim Luiz de Queiroz, promotor da Comarca e colaborador do Correio do São Francisco, que circulou de 1901 a 1911. Para o autor, Joaquim Luiz de Queiroz era um "jornalista primoroso, pelo estilo, pela profundeza dos conceitos filosóficos, pela elevação moral e sabedoria". José Inácio da Silva, médico e depois deputado, também é retratado como um profissional da imprensa.

É importante ressaltar que, ao selecionar estes dois personagens como homens da imprensa, Fernandes Cunha associou a prática jornalística à habilidade literária. Eram também homens públicos, responsável por acolher, recomendar e dar aceitação social aos que chegavam para residir na cidade e ousar ser jornalista.

Foi o que aconteceu com o jovem Eugênio Lima, alagoano que fora morar na cidade e fundou o Folha do São Francisco, em 1912. José Inácio encaminhou-lhe uma carta, parabenizando por ser um "um moço de tão fino 
quilate", homem virtuoso com a nobre missão de produzir um jornal e educar a população, livrando-a de vícios associados à falta de uma cultura letrada.

$\mathrm{Na}$ sua narrativa, Fernandes Cunha se referiu a outros jornalistas como o professor João Leal pelo estilo "combativo, ardoroso e veemente nas lutas que combateu"; Joaquim Quinaud, de A Luta, por ser um veículo de reivindicações populares; e Aprígio Araújo, responsável pela publicação de $O$ Echo, "com os seus magníficos editoriais, ora apoiando e aplaudindo as iniciativas do poder público, ora combatendo, com veemência e segurança os desacertos da administração". A imprensa exercia a mediação na esfera pública.

João Fernandes da Cunha também narra a participação como jornalista e fundador de $O$ Arauto, junto com o companheiro Antonio Cursino. Ele se considerava um jovem idealista que se dispôs a publicar um jornal "que pudesse servir de veículo às expansões intelectuais da mocidade juazeirense e de todos aqueles que se interessassem pela literatura" (1978, p. 143).

O autor também vai denominar Olegário Assis como um dos jornalistas que se propôs a editar $O$ Diário de Juazeiro. Porém, o autor não discrimina as origens desse jornalista, qual a sua profissão e o ano em que publicou. Sabemos que a memória é resultante de seleção, mas nos parece sintomático que não haja informações com maior profundidade sobre este tipógrafo e jornalista, que fundou dois jornais na cidade, o Diário de Juazeiro, O Juazeiro e trabalhou em $O$ Echo. Olegário de Assis é irmão de José Diamantino de Assis, que não é mencionado no livro como jornalista, embora tenha publicado impressos, dos anos de 1929 a 1969, sendo que, hoje, ainda podemos encontrar exemplares dos jornais.

Percebemos que a dimensão do esquecimento esteve presente nessa narrativa pelo apagamento de rastros sobre a trajetória de alguns jornalistas. Como diz Paul Ricouer (2007, p. 455), como uma narração exaustiva é perfeitamente impossível, opera-se uma seleção. Pode-se narrar suprimindo, deslocando ênfases, refigurando os personagens da ação como os seus contornos, entre outras estratégias, algumas de natureza ideológica outras da própria trama narrativa. 
Ao ler a obra de João Fernando da Cunha verificamos lacunas sobre a caracterização da linguagem jornalística e do conteúdo, entre outros aspectos que são importantes hoje para se construir uma história da imprensa. Mas os fragmentos desse passado trazidos pelo autor nos indicam que os jornais participaram da construção de redes de sociabilidade.

Ao verificar a redução da impressão de jornais, na década de 1950, o autor procurava explicações para o desaparecimento de alguns periódicos. "Lastimávamos, então, que desfrutando a sede do nosso município de grande desenvolvimento, alcançando situação impar em todo o sertão e zona de São Francisco, houvesse regredido no particular da imprensa, de modo tão notório, uma vez que aí já haviam existido e prosperado, simultaneamente, três bons jornais (CUNHA, 1978, p 143)".

Por meio de suas lembranças pessoais, procuramos encontrar indícios também das dificuldades de outros comunicadores, pois, embora a memória tenha uma dimensão individual, os seus quadros de referência são sociais e são eles que permitem que "tenhamos também uma memória intersubjetiva, uma memória compartilhada, uma memória coletiva", como afirma Maurice Halbwachs (2004, p. 53).

A partir desses indícios, conseguimos perceber que a sustentabilidade dessa imprensa era precária, alguns jornais enfrentavam dificuldades econômicas. Ao se referir ao desaparecimento do Arauto, publicado em 1939, João Fernandes da Cunha narrou: "exclusivamente literário não encontrou o respaldo financeiro que the permitisse vida longa. Ressurgiu, mais tarde, como semanário noticioso, em cuja fase mereceu, ainda, a nossa colaboração, mas voltou, também por dificuldades de ordem econômica, ao sono dos justos" (1978, p.143).

No conjunto dessas lembranças compartilhadas, verificamos silenciamento sobre a trajetória de alguns jornais, pois o autor silencia, apaga do seu relato a existência de jornal na década de 1950 e 1960. Chega a relatar que atravessamos um longo período sem imprensa na cidade. Contudo, em pesquisa no acervo da Fundação Museu Regional do São Francisco, constam as edições de Tribuna do Povo, editado por José Diamantino de Assis e Jorge 
Gomes, vereador pelo Partido Social Democrata (PSD) na década de 1950 e 1960, sendo preso no golpe de 1964, acusado de subversão, embora sem provas, como posteriormente, o Exército Brasileiro tornou público, em 1965.

Ainda não sabemos as origens do silêncio a respeito de alguns personagens da imprensa. Sabemos que a narrativa sobre o passado não abarcaria todos os acontecimentos, pois as lembranças são moventes, complexas, dependem dos vários quadros de referência e das comunidades afetivas que o autor compartilhou.

Para perceber possíveis lacunas, é importante verificar como outros autores, a exemplo de Walter de Castro Dourado (1978), constroem uma representação dessa imprensa e o que ele acrescenta a essa construção histórica.

\section{Walter de Castro Dourado e a síntese histórica sobre o jornalismo juazeirense}

Walter de Castro Dourado atuou como jornalista, colunista literário e redator de programas radiofônicos na Rádio Juazeiro. Foi membro fundador da Associação da Imprensa Juazeirense, trabalhou no Ginásio Rui Barbosa e foi proprietário da Escola Remigton em Juazeiro, autorizada pela Secretaria de Educação e Cultura do Estado a emitir diploma de técnicas datilográficas.

$\mathrm{Na}$ década de 1980, ele publicou os livros Juazeiro da Bahia à luz da História nos quais narra o povoamento da cidade, a trajetória política, econômica; e foi autor de perfis biográficos de personalidades locais. Nascido em 1909 na cidade baiana de Casa Nova, ele fez o curso ginasial em Alagoinhas e participou, nos anos de 1940, da criação de Cooperativa Mista de Consumo e Crédito no município, junto com ex-prefeito e professor Edson Ribeiro.

Um dos primeiros textos de Walter de Castro Dourado sobre a imprensa foi publicado em 1972 no jornal Rivale, com o título Síntese Histórica do Jornalismo Juazeirense. Essas informações foram incorporadas no artigo $A$ 
imprensa e vultos importantes do passado em Juazeiro, publicado na coletânea Juazeiro ano 100, Lances de sua história (1978).

Na coletânea, Walter de Castro Dourado faz uma caracterização dos pequenos jornais que proliferaram na cidade. Ele os considerava pequenos folhetins, semelhantes aos pasquins que circularam no século XIX e foram instrumentos de luta política. Os títulos dos jornais, inclusive, demonstravam a verve satírica como $O$ furação, $A$ Trombeta, Esbodega, entre outros.

Walter de Castro Dourado destaca a participação de uma imprensa política, como O Joazeiro, vinculado ao Partido Republicano Democrata, em 1920, para atender as demandas dos projetos políticos locais. O autor também traz informações sobre a imprensa operária - O Trabalho - editada nos anos de 1930 pela Associação Beneficente dos Artífices Juazeirenses, em defesa dos interesses dos trabalhadores de ofícios (alfaiates, marceneiros), do transporte fluvial e ferroviário. Em 1932, sob a direção do professor Agostinho José Muniz e do marceneiro Saul Rosas, que foi filiado ao Partido Comunista do Brasil (PCB), o jornal colocou-se em oposição ao governador Juracy Magalhães e foi empastelado, acusado de promover a organização dos trabalhadores.

Walter de Castro Dourado também traz pequenas descrições de jornais e jornalistas como Aprígio Araújo, de O Echo, jornal que circulou de 1920 até a década de 1940; e o tipógrafo José Diamantino Assis, que fundou vários jornais e considerado um homem com "tenacidade, inteligência" e "interessado em dotar a cidade de órgãos noticiosos" produzidos a partir de sua pequena tipografia.

$\mathrm{O}$ autor registrou também a presença da imprensa estudantil como $O$ Cacto, feito por jovens estudantes da Faculdade do Médio São Francisco (Famesf) entre 1964 e 1965. No artigo publicado, Walter de Castro Dourado se referiu as dificuldades de publicar impressos, inclusive os riscos da profissão, como acidentes de trabalho. Em 1959, Alberto Bezerra Mariano sofreu um acidente na prensa automática ao trabalhar na edição do O Democrata. Devido ao acidente, o tipógrafo interrompeu as atividades de impressão.

Ao longo dos anos de 1970 e 1980, outros jornais como Tribuna do São Francisco, Jornal de Juazeiro, Últimas Notícias Vip, Gazzeta do Vale são 
publicados na região com mudanças no padrão gráfico de impressão, alguns com policromia, e com uma linguagem informativa. Contudo, essa trajetória não é explorada nas obras de Walter Castro Dourado e João Fernandes da Cunha que centralizaram a narrativa do final do século XIX até os anos de 1950.

Apesar de possíveis lacunas na narrativa, as obras dos jornalistas João Fernandes da Cunha e Walter de Castro Dourado construíram uma memória sobre a imprensa local, cujos fragmentos podem colaborar para desvelar 0 passado e a trajetória de comunicadores ao serem interpretados no cruzamento de fontes diversas.

\section{CONSIDERAÇÕES}

A possibilidade de termos acesso ao passado está relacionada com a forma como podemos acionar as nossas memórias, os artefatos e os documentos. Uma sociedade que despreza o passado pode perder os laços de referência com os grupos sociais e não consegui relacionar o presente às experiências passadas nem futuras. Se assim for, os nossos horizontes de expectativa se fundam no eterno presente, que impede de nos conectar com as experiências vividas e de nos situarmos em uma relação temporal.

O culto ao passado (ou o excesso de sedução por uma cultura da memória) também pode nos imobilizar, pois pode fazer com que não valorizemos as experiências do tempo presente. Contudo, a memória é vital para entender o passado. Daí a importância do ato de relembrar. Para David Lowenthal, lembranças são reconstruções ecléticas, seletivas baseadas em ações e percepções, através das quais delineamos, simbolizamos e classificamos o mundo.

Por isso, a importância de investigar como no passado os homens compreenderam a imprensa, como eles refletiram sobre o próprio fazer e quais narrativas eles legaram ao presente. As obras, de natureza histórica, são em grande parte testemunho de uma época que os autores julgavam que documentos, o patrimônio arquitetônico e as pessoas estavam em vias de desaparecimento. 


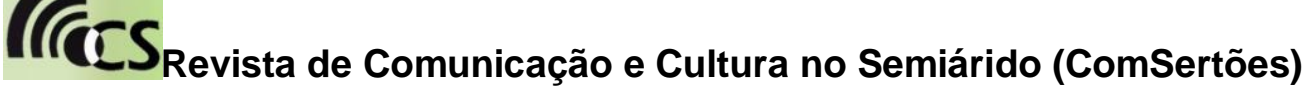

Por isso, João Fernandes da Cunha e Walter de Castro Dourado assumiram o papel privilegiado de narradores, como senhores da memória para as futuras gerações. As obras são, em sua maioria, artefatos que procuram descrever o passado, já que a maior parte dos primeiros jornais da primeira metade do século XX ainda não foi conservada.

Essas obras são um ponto de partida para problematizar questões sobre a imprensa. Produtos de uma época, os relatos narram uma parte do que aconteceu a partir dos processos de seleção no conjunto dos grupos sociais e comunidades afetivas com os quais os autores compartilharam visões de mundo e experiências. Cabe-nos, como pesquisadores, interpretá-los e submetê-los a uma crítica sobre a própria natureza do documento, verificando os vestígios de um tempo passado que ficou como um legado ao presente. 


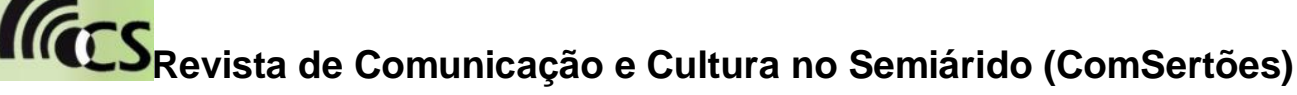

\section{REFERÊNCIAS}

CERTEAU, Michel. A Escrita da história. $2^{\mathrm{a}}$ Ed. Rio de Janeiro: Forense Universitária, 2008.

CUNHA, João Fernandes. Memória Histórica de Juazeiro. Juazeiro-Ba. Ed. Autor. Juazeiro-Ba. 1978.

DUARTE, Jorge de Souza. Juazeiro: nos caminhos da história. Juazeiro-Ba. Edição do autor. 1985.

DOURADO, Walter. A imprensa e os vultos do passado de Juazeiro, ano 100. In: DUARTE, Jorge; DOURADO, Walter et alli. Juazeiro ano 100: lances de sua história. Salvador: Empresa Gráfica da Bahia, 1978.

DOURADO Walter de Castro. Juazeiro da Bahia à Luz da História. Vol I. Impressora Rocha. Studio Domingues, Juazeiro - Bahia, 1985.

DOURADO Walter de Castro. Juazeiro da Bahia à Luz da História. Vol II. Gráfica Beira Rio. Juazeiro - Bahia, 1994.

DIAS, Wilson. História da Imprensa em Juazeiro. Juazeiro: Gráfica Santa Inês, 1982.

HALBWACHS, Maurice. A memória coletiva. São Paulo: Centauro, 2004.

LE GOFF, Jacques. História e memória. Campinas, Editora da Unicamp, 1994.

LOWENTHAL, David. Como conhecemos o passado. São Paulo: Projeto História, vol 17.. nov 1998.

NORA, Pierre. Entre memória e história: a problemática dos lugares. In: Projeto História. São Paulo: vol 10, dez 1993.

RICOUER, Paul. A memória, a história, o esquecimento. Campinas. Editora da Unicampo, 2007. 